\title{
Land use Land Cover Change Detection of Gopala Extension, Shivamogga, using RS, GIS and GPS- A Case Study
}

\author{
Ganesh Prasanna S \\ ${ }^{1}$ Assistant Professor, \\ Department of Civil Engineering, JNNCE, \\ Shivamogga
}

\begin{abstract}
Only a few landscapes are left on the earth which is still in their natural state. After the advent of the modern man, due to civilization and urbanization the earth surface has undergone severe wear and tear resulting in the serious changes in the natural phenomenon of the earth. It has also had a profound effect upon the natural environment, which results a change in the pattern of the land use and land cover over time. Land use and land cover refers to the physical characteristics of the earth surface, captured in the distribution of vegetation, water bodies, rock /soil, artificial cover and other physical features of the land including those created solely by human activities. Remote Sensing and GIS technique is a powerful tool in providing reliable information on various natural resources of a region. Remote sensing and GIS is also an effective tool for analysis of land use issues and for land cover planning and modeling. By understanding the driving forces of land use development in the past, managing the current situation with modern GIS tools, and modeling the future, one is able to develop plans for multiple uses of the natural resource and nature conservation. Information on land use and land cover are available in the form of maps and the data is very important for planning, management, and utilization of land for agriculture, forestry, urban and town planning, industrial, environmental studies and economic development. In this study an attempt has been made to understand the land use and land cover change pattern observed in the Gopala Extension of Shivamogga district combining the techniques of RS and GIS.
\end{abstract}

Keywords: Civilization, Urbanization, Land use, Land cover, Remote Sensing, GIS.

\section{INTRODUCTION}

Land is the most important natural resource on which all human activities are based. Growing population and human activities have increased the demand of limited land and soil resources for the agriculture, forest, pasture, urban land and industrial land uses. Information on the rate and kind of changes in the use of land resources is essential for proper planning and management. Further, land use data is needed in the analysis of environmental process and problems. Land cover is a fundamental parameter describing the earth's surface. Changes in land use can be due to urban expansion and loss of agriculture land, changes in the river regime, and the effect of shifting cultivation, the spread of erosion and desertification and so on. This requires not only the identification of features but also the comparison of subsequent data in order to recognize, when rapid changes has taken place. Various hydrological processes such as interception, infiltration, evaporation, evapo transpiration, soil moisture, runoff and ground water recharge are also influenced by land use / land cover characteristics of the region.

Urban sprawl describes the fast expansion of city away from central urban areas. This sprawl causes many negative effects in all the areas including resources production to consumption. Urban sprawl has become a current issue both for academic planners and administrators and its effects in metropolitan areas can be summarized as follows:

1. Increased use of cars and traffic jams causes environmental pollution.

2. Expansive water, road network and infrastructure system.

3. Lack of functional open space agriculture area loss.

4. Lack of accessibility.

5. Intensified and dense poverty along with ethical and economical disintegration.

\section{AIM AND OBJECTIVES}

The main aim of this study is to use spatial and non spatial approaches in measuring urban sprawl of Gopala Extension, Shivamogga city between time periods of 1998, 2012 and 2018. We selected the time interval between 1998 , 2012 and 2018 because of the availability of the data. A spatial modeling approach is one that employs GIS analysis techniques such as buffering and reclassification of data. Buffering refers to create a zone wherein urbanization may occur along highways, with the following objectives:

To prepare the base map of the region with the selected area using the Survey of India (SOI) topomaps, cadastral map and Google satellite images.

To generate resource maps of various themes such as settlements, built up area and transport network maps with the help of topomaps, cadastral map as well as satellite imagery.

Providing in situ on how LU/ LC has changed in the region of selected area between the periods 2012 and 2018 i.e.., 6 years in order to demonstrate the impact of LU/ LC changes. 


\section{STUDY AREA}

The study area lies in Shivamogga district of Karnataka State having an area of $2.566 \mathrm{sq} \mathrm{km}$ and located between Latitudes $13^{\circ} 55^{\prime} 47^{\prime \prime}$ to $13^{\circ} 56^{\prime} 37^{\prime \prime}$ and Longitudes $75^{\circ} 31^{\prime} 53^{\prime \prime}$ to $75^{\circ} 33^{\prime} 25^{\prime \prime}$. The population in the study area during the year 1998 was 5102 which increased to 15674 in the year 2012 and presently it has a population of 30312 in the year 2018 . The average distance from the city is $2 \mathrm{kms}$ from the bus stand.

\section{METHODOLOGY}

The present study has been carried out for the land use and land cover analyses to ascertain the urban sprawl in the area using Survey of India (SOI) topo sheet bearing no 48 O/15 of 1:50000 scale which covers Shivamogga city. SOI topo sheet along with Google satellite image of the year March - 2012 and March - 2018 respectively were used for generation of various thematic layers such as land use and land cover, road network, settlements and drainages. GPS - Oregon 550 with an accuracy of $0.5 \mathrm{~m}$ was used all along to collect the ground truth data. Later all the generated layers were integrated in GIS mode using Arc View and Map Info software to generate the final map for analysis.

The study area was divided into three classes comprising of Built up land, Agricultural Land and Water Bodies. Built up land comprises of both Urban and Non Urban areas in the Extension cities. Agricultural land comprises of Plantations, Fallow land and Double Crop Land i.e, Kharif crop and Rabi crop. Water bodies are identified in the form of tanks.

Transport network map was also prepared to know the accessibility in the area. The area comprised of a National Highway which measured a length of $1,721 \mathrm{~m}$ and district highway which measured a length of $8,899 \mathrm{~m}$ which were made up of Asphalt and other sub roads comprised of about 47,200 m which were made up of concrete pavements.

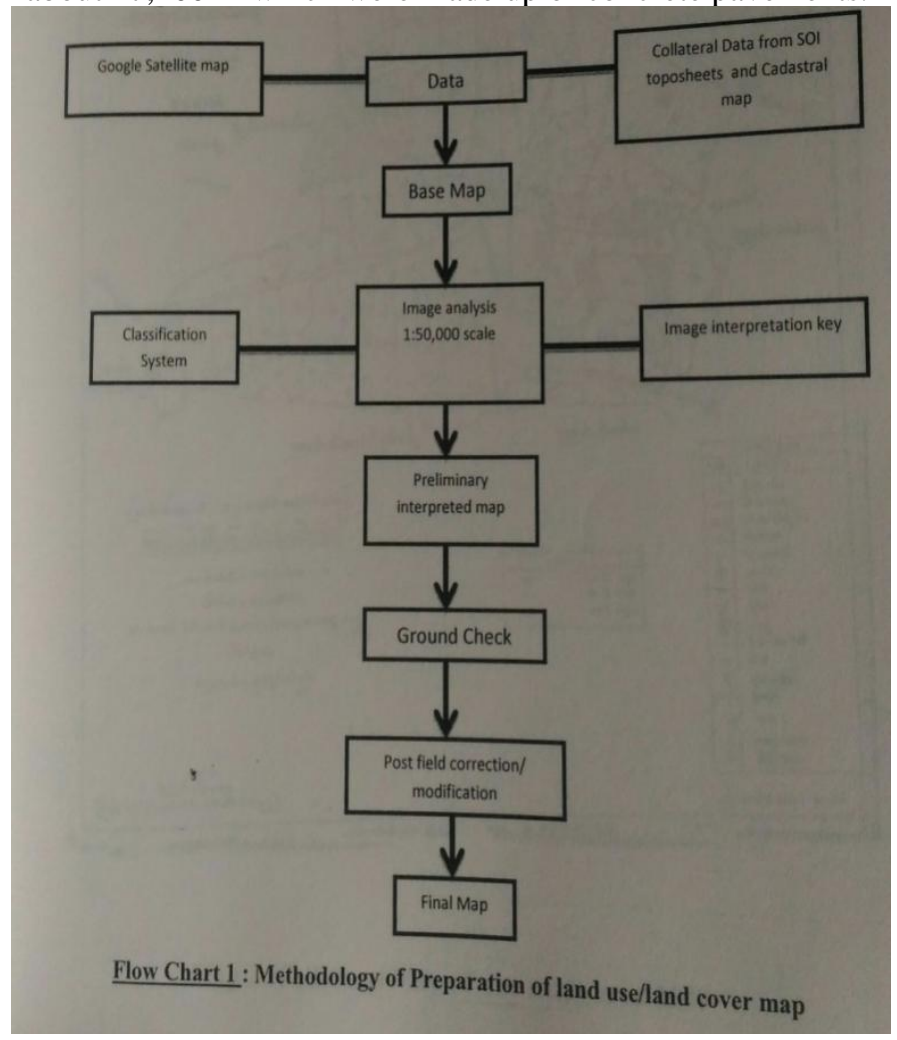

\section{RESULT AND DISCUSSION}

The data pertaining to land use and land cover analyses obtained during the present study is summarized in table 1 . The data shows that during the past two decades there is an increase in the area of built up land, which in turn has decreased the water bodies in the area and also there is a decrease in the agricultural land and plantations. In 1998 the urban land comprised of approximately $1 \%$ of the study area, in 2012 urban land accounted for approximately $14 \%$ of the study area, and in the year 2018 urban land accounted approximately for $75 \%$ of the study area. This shows that the urban built up land increased enormously during the year $2012-2018$ which accounted for approximately 51\% increase in the area. During the year 1998 about $2.34031 \mathrm{sq} \mathrm{km}$ of the study area was comprised of Agricultural land, tanks comprised of about $0.175 \mathrm{sq} \mathrm{km}$ and urban built up land comprised of about $0.05069 \mathrm{sq} \mathrm{km}$.

\section{CONCLUSION}

This study gives a good insight into the Gopala Extension land use land cover changes during the last two decades. It is observed that there is an enormous increase in the built up land which accounts for $75 \%$ of the study area. Tanks and 
agricultural land has decreased over the time which in turn may lead to water logging problem in the area. All the tanks are filled with soil and have been converted into residential areas. If proper drainage system is not adopted then there are chances in the rear future that the low lying areas may have severe flooding problem. Proper planning is required as the extension is a part of smart city.

\begin{tabular}{|l|l|l|l|}
\hline Class Name & Area (1998) in Sq Km & Area (2012) in Sq Km & Area (2018) in Sq Km \\
\hline Agricultural Land & 2.34031 & 2.2516 & 0.644 \\
\hline Tanks & 0.175 & 0.000 & 0.000 \\
\hline Urban land & 0.05069 & 0.3643 & 1.922 \\
\hline Population & 5102 & 15674 & 30312 \\
\hline Households & 1080 & 3404 & 6682 \\
\hline
\end{tabular}

TABLE 1
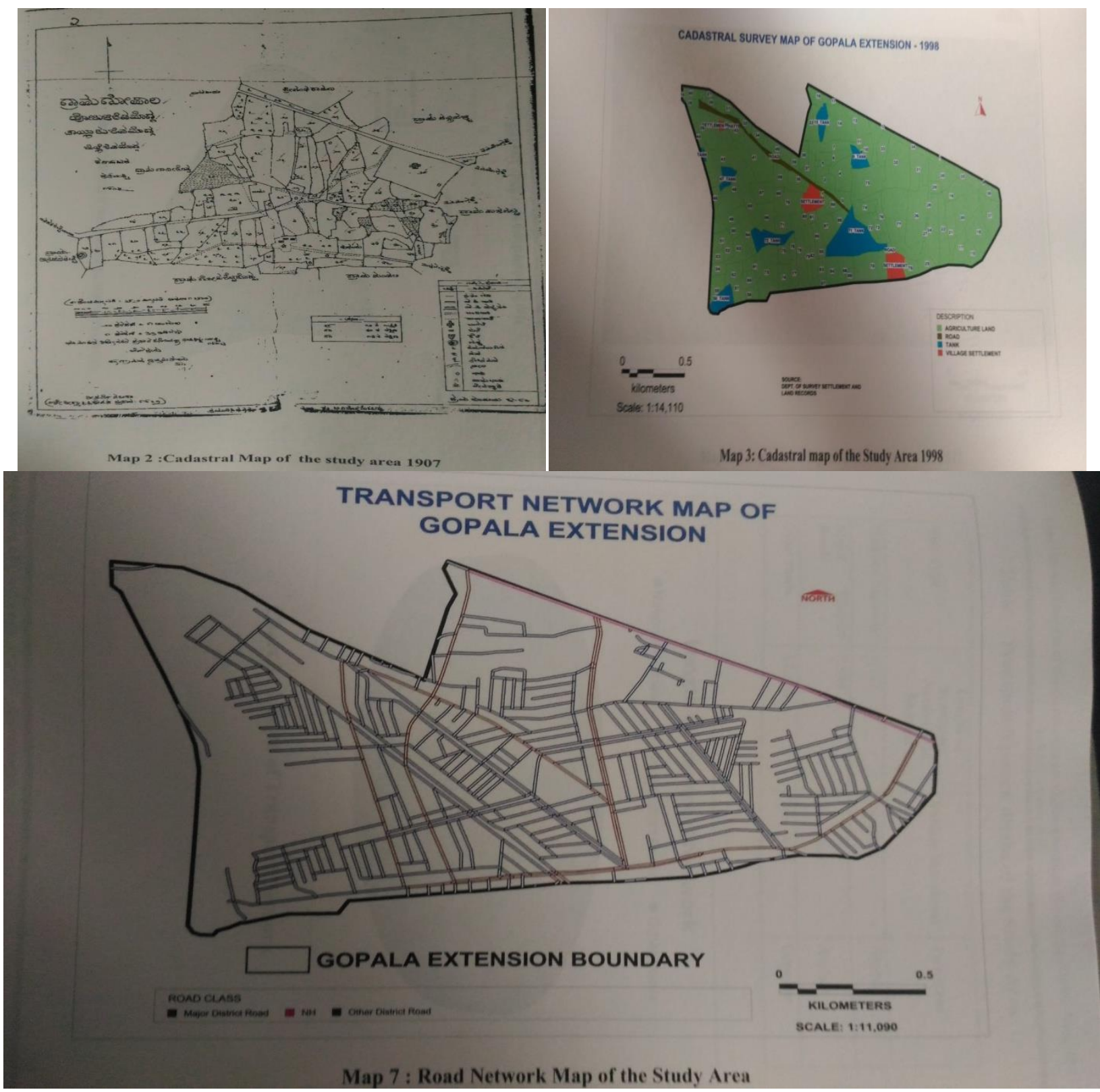

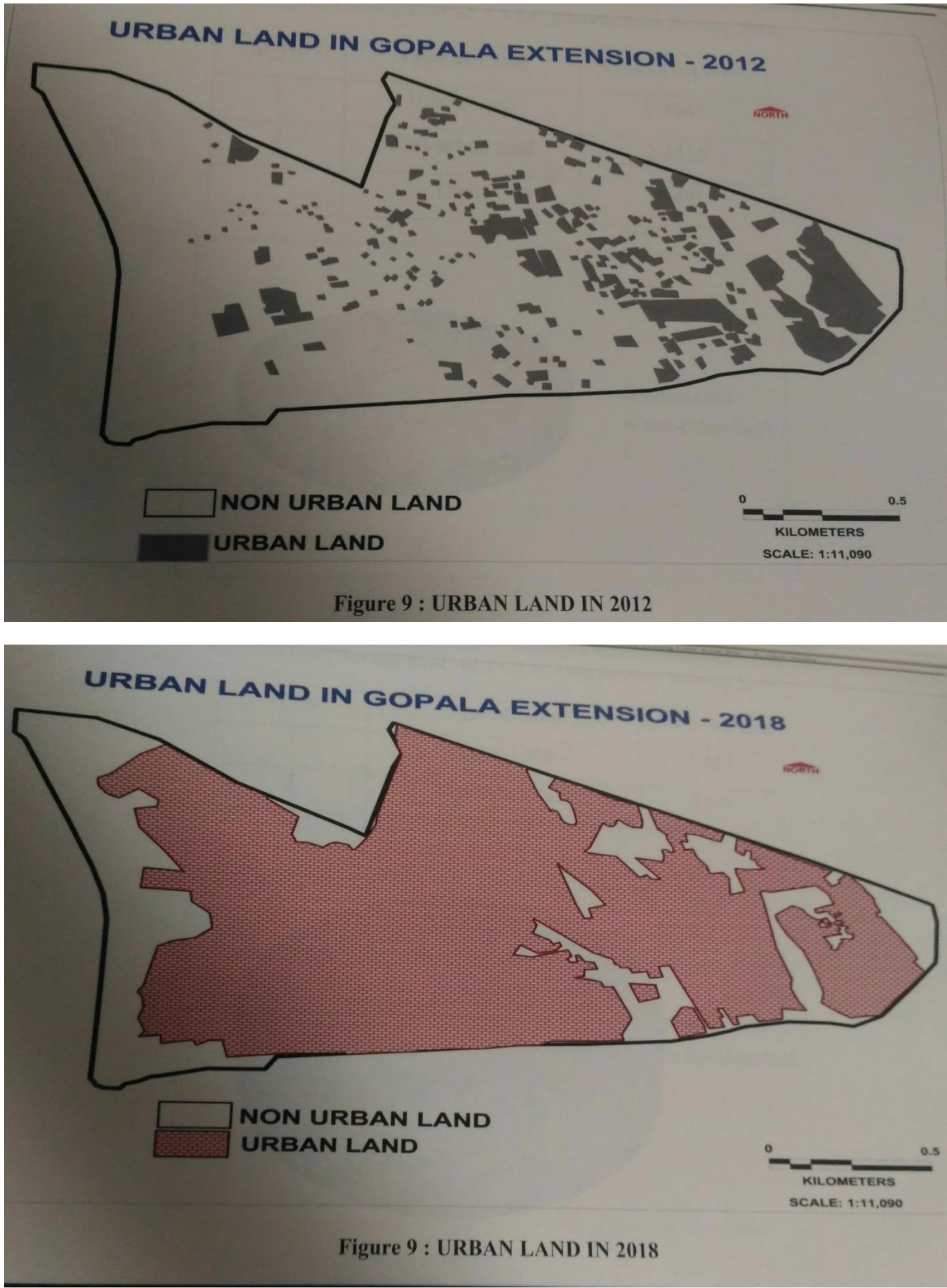

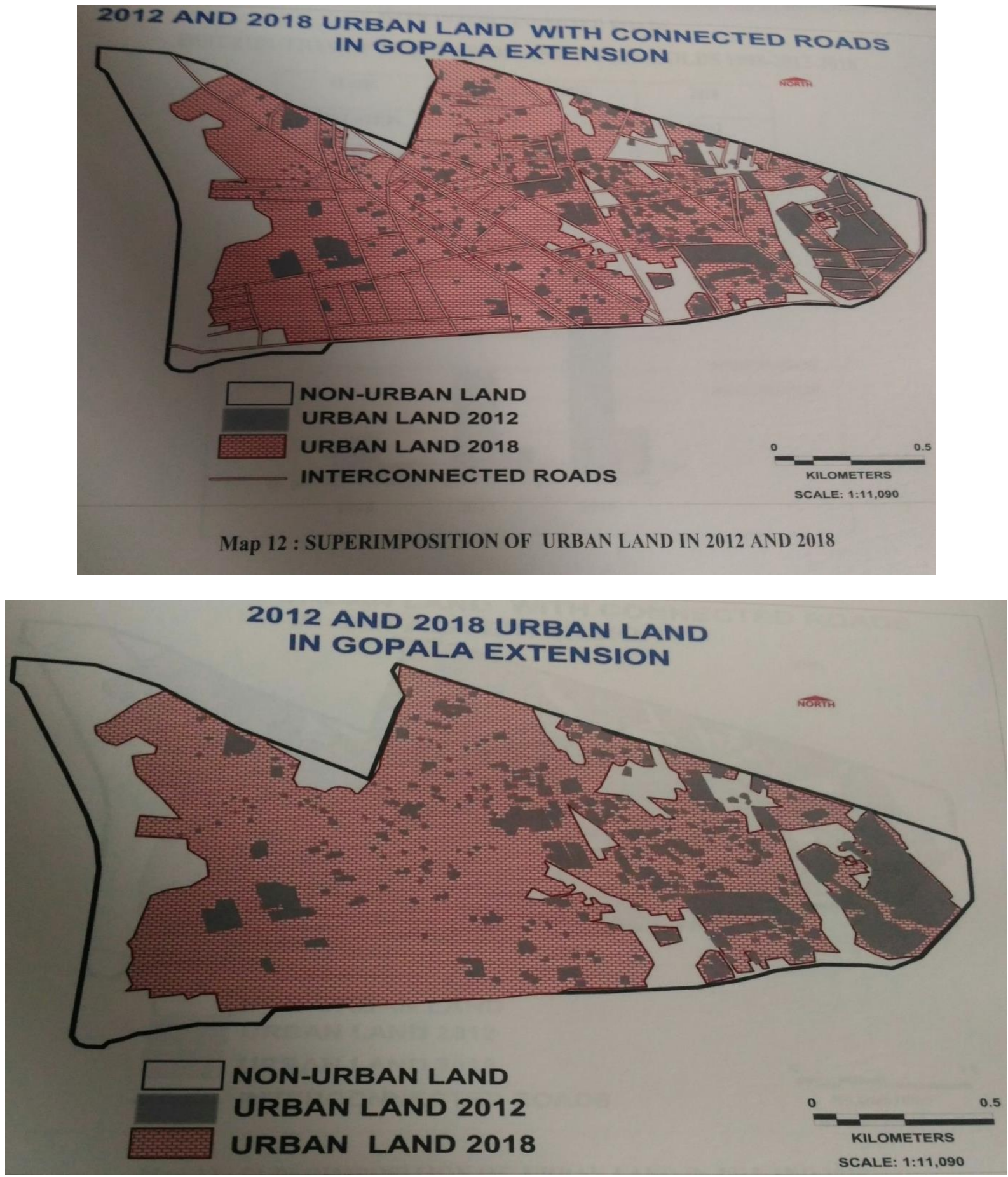


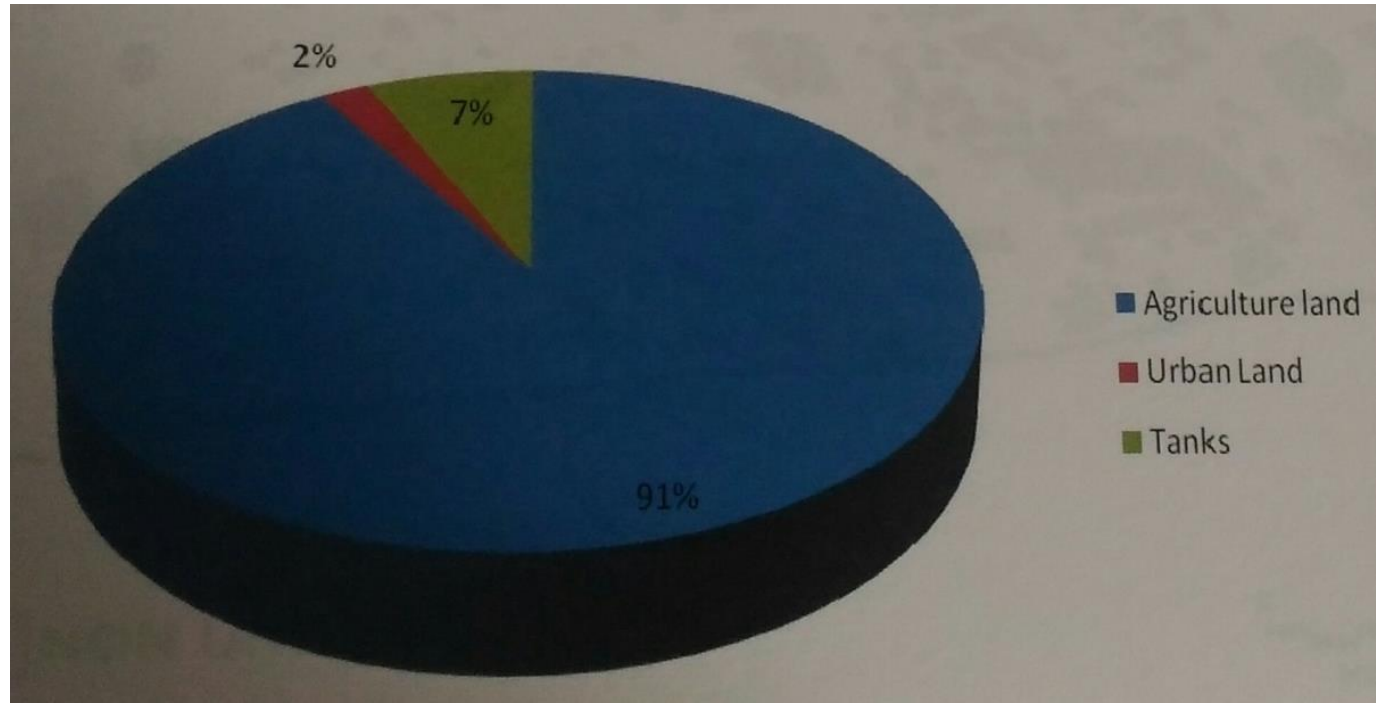

Percentage of changeover of Land Use Land Cover Distribution during 1998

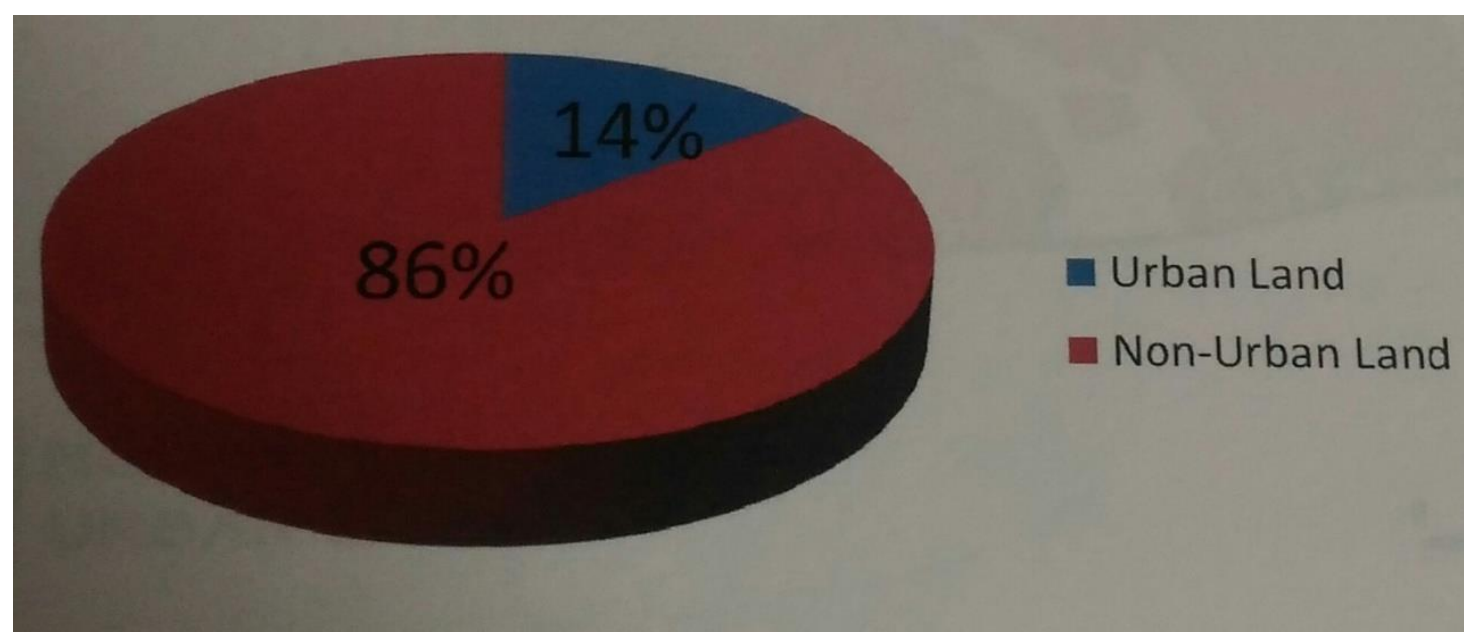

Percentage of changeover of Land Use Land Cover Distribution during 2012

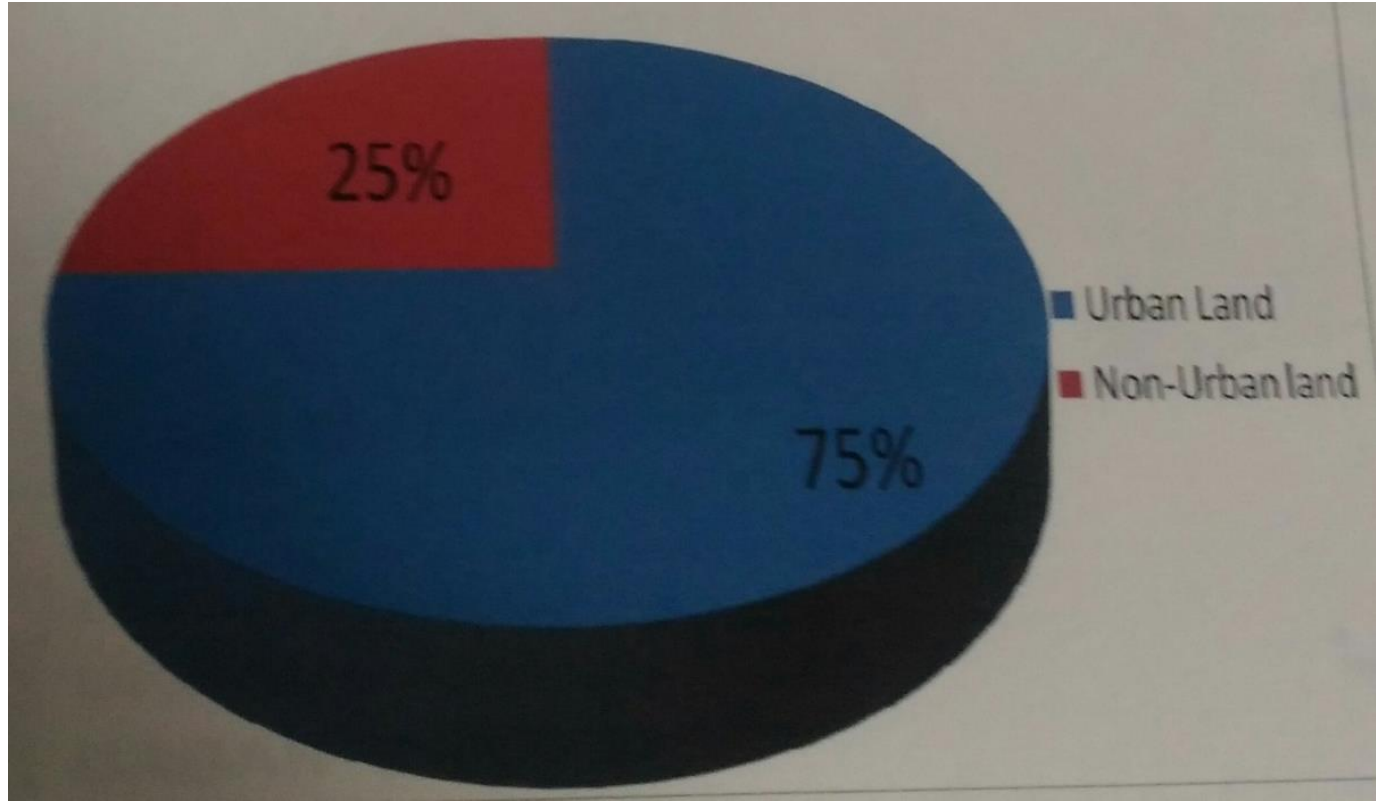

Percentage of changeover of Land Use Land Cover Distribution during 2018 


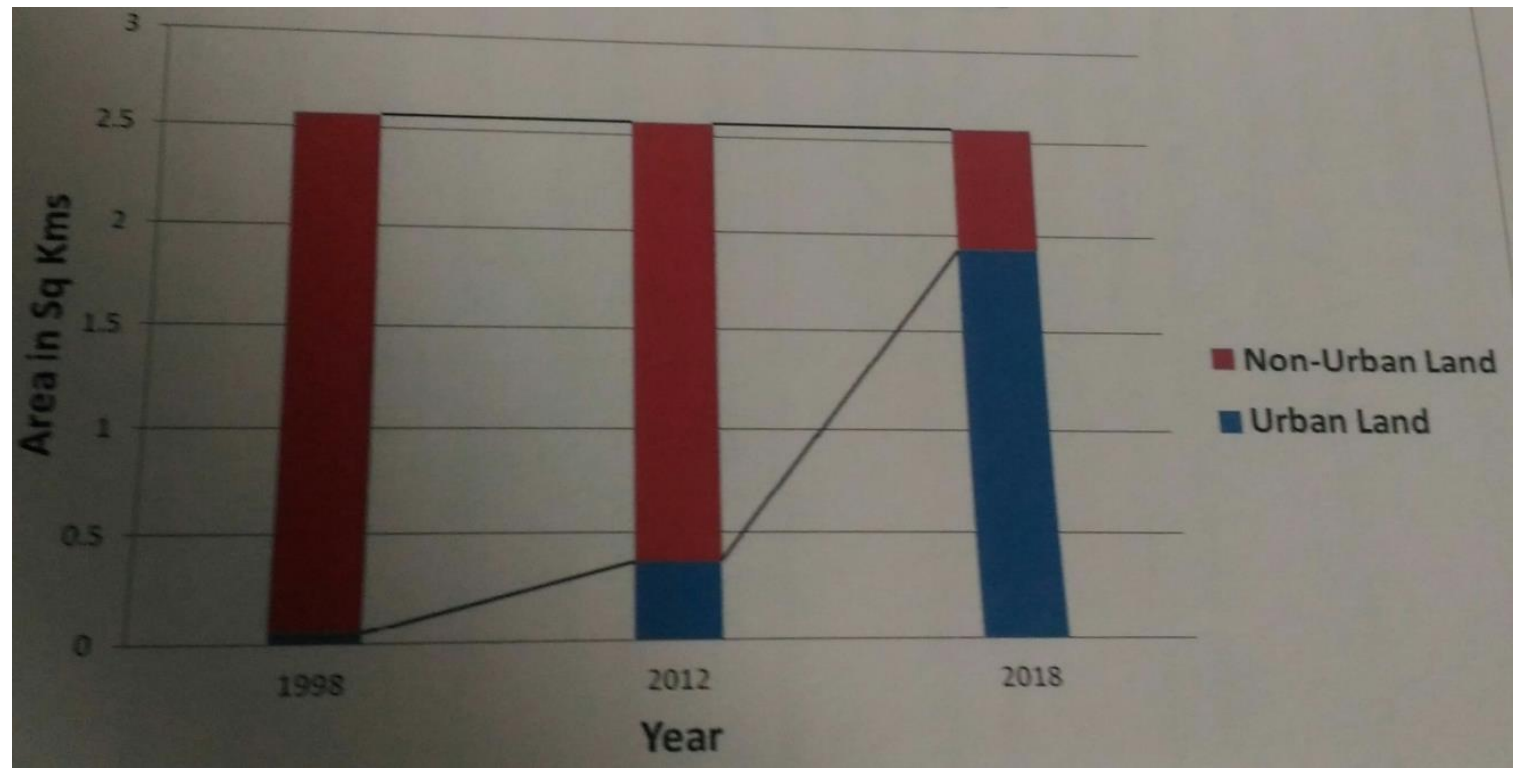

Comparison of LU/ LC changes during the years $1998-2012-2018$

\section{REFERENCES}

[1] Lousia, J.M.J and Antonio, D.G (2001). Parametric Land Use and Land Cover Classification as tools for environmental change detection. Agric.Ecosyst.Environ. 91, pp 89-100

[2] Anderson (1991). Geographic Information Sysytem, A Management Perspective. WDL Publications, Ottania

[3] B.S Bisht and B P Kothyari, (2001), Land cover change analysis of Garurganga Watershed using Remote Sensing and GIS Techniques. Journal of Indian Society of Remote Sensing, 29(3), pp 165- 174

[4] Jaisawal R K, Saxsena R and Mukherjee S (1991). Application of Remote Sensing Technology for Land use and Land cover change analysis. Journal of Indian Society of Remote Sensing, 27(2), pp 123- 128.

[5] Roy, D.P. (2002). Remote Sensing for Sustainable Development, Journal of Indian Society of Remote Sensing, 19 (A), pp 217 - 235.

[6] Roy, P.S and Giriraj, A., (2008), Land use and Land cover analysis in Indian context, Journal of Applied Sciences. 8(8), pp 1346- 1335 